\title{
A morte como fim do projeto de ser: um estudo dos últimos anos de Sartre
}

\section{La muerte como final del proyecto de ser: un estudio de los últimos años de Sartre}

\section{Death as the end of the project of being: a study of the last years of Sartre}

\author{
Wagner Alexandre Lara ${ }^{a}$ - e Ismael Ferreira ${ }^{b}$ \\ ${ }^{a}$ Formado em Bacharel em Psicologia pela Escola Superior de Criciúma-ESUCRI, Pós-Graduação em Docência no Ensino Superior \\ pelo Centro Universitário Leonardo da Vinci-UNIASSELVI. Email: wagner-la@hotmail.com \\ ${ }^{\mathrm{b}}$ Formado em Psicologia pela UNESC, Pós-Graduação em Psicologia Fenomenológica Existencialista Sartreana na UNISUL. \\ Docente na Esucri e na Formação em Psicologia Existencialista do Centro de Desenvolvimento e Integração Humana Simone de \\ Beauvoir. E-mail: ismael@esucri.com.br
}

Resumo: Ao abordar a temática que envolve a morte como fim do projeto de ser, este estudo propõe analisar a terminalidade humana. Para tanto, iniciará introduzindo os princípios essenciais da psicologia fenomenológica existencialista sartreana. Sendo assim, deve-se observar como se dá o processo de construção do projeto de ser, compreendendo que todo indivíduo tem esse projeto em seu viver e o mesmo só terá fim quando o ser se encontra com a morte. Portanto se deve observar que na existência humana todo ser está em direção a um fim, pois desde que lançado ao mundo ele passa a ter uma possibilidade de não estar mais aí. Desse modo, o estudo dos últimos anos de Jean-Paul Sartre contidos no livro “A cerimônia do adeus" (2012) pode ajudar a compreender todo esse processo de construção do projeto de ser, bem como conhecer o caminho de finitude do escritor existencialista.

Palavras-chave: Projeto de Ser; Jean-Paul Sartre; Escolhas; Morte.

Resumen: Al abordar el tema que involucra la muerte como el final del proyecto de ser, este estudio propone analizar la terminalidad humana. Con este fin, comenzará introduciendo los principios esenciales de la psicología fenomenológica existencialista sartreana. Por lo tanto, uno debe observar cómo se lleva a cabo el proceso de construcción del proyecto del ser, entendiendo que cada individuo tiene este proyecto en su vida y que solo terminará cuando el ser se encuentre con la muerte. Por lo tanto, debe tenerse en cuenta que en la existencia humana cada ser está hacia un fin, ya que, dado que se

Como citar o artigo: LARA, W. A.; FERREIRA, I. A morte como fim do projeto de ser: um estudo dos últimos anos de Sartre. Revista de Ciências Humanas, Florianópolis, v. 53, 2019 DOI: 10.5007/2178-4582.2019.e58214 você pode compartilhar, adaptar, para qualquer fim, desde que atribua a autoria da obra, forneça um link para a licença, e indicar se foram feitas alterações. 
lanza al mundo, tiene la posibilidad de no estar más allí. De esta manera, el estudio de los últimos años de Jean-Paul Sartre contenido en el libro "La ceremonia del adiós" (2012) puede ayudar a comprender todo este proceso de construcción del proyecto del ser, así como a conocer el camino de la finitud del escritor existencialista.

Palabras clave: Proyecto del ser; Jean-Paul Sartre; Elecciones; Muerte.

\begin{abstract}
When approaching the theme that involves death as the end of the project of being, this study proposes to analyze human terminality. To this end, it will begin by introducing the essential principles of Sartrean existentialist phenomenological psychology. Therefore, one must observe how the construction process of the project of being takes place, understanding that every individual has this project in their living and it will only end when the being meets with death. Therefore, it should be noted that in human existence every being is towards an end, since once it is launched into the world, it has the possibility of not being there anymore. In this way, the study of the last years of Jean-Paul Sartre contained in the book "A Farewell to Sartre" (2012) by Simone De Beauvoir can help to understand all the process of construction of the project of being, as well as to know the existentialist writer's path of finitude.
\end{abstract}

Keywords: Project of Being; Jean-Paul Sartre; Choices; Death.

\title{
1 INTRODUÇÃO
}

O presente artigo visa levantar uma discussão sobre os aspectos da morte e a finitude dos seres humanos, com intuito possibilitar uma reflexão sobre a morte como fim do projeto de ser, um assunto muitas vezes tido como um tabu ou velado na sociedade atual e não discutido em profundidade no meio acadêmico. Embora seja algo comum a todos os seres humanos e muito significativo no processo de desenvolvimento dos mesmos. Por isso tem uma grande relevância o estudo do fim do projeto de ser, pois busca tentar entender melhor o fenômeno da finitude humana ao abordar o assunto pautado em uma psicologia científica. Para tal proposta, busca-se um embasamento teórico e metodológico, na psicologia fenomenológica existencialista sartreana, fazendo um estudo dos últimos anos da vida de Sartre na ótica de Simone de Beauvoir, nos relatos sobre o processo de morte do escritor existencialista contidos no livro "A Cerimônia do Adeus".

Para criar uma discussão em torno da morte como fim do projeto de ser, se faz necessário entender o que é esse projeto, visto que se trata da discussão central no existencialismo. Segundo Schneider (2011), o projeto se caracteriza na busca do ser humano, em se realizar plenamente, já que desde sua existência o ser humano está sempre em direção a um futuro, não havendo a possibilidade de existir um indivíduo sem projeto, pois desde que o ser humano se lança ao mundo ele parte em busca de um fim, mesmo sem ter clareza do que é esse fim e como acaba esse projeto. Sendo assim, uma totalização em curso, movido por uma dinâmica psicológica que constitui o sujeito no mundo como um projeto, ao mesmo tempo em que esse se torna um ser rumo a morte.

Segundo Sartre (2015), ao ser lançado ao mundo, o ser humano tem um princípio e um término, visto que seu viver é um projeto de totalização em curso. Assim, ao se lançar sobre o mundo, tem como uma de suas possibilidades a finitude. Com isso aparece aqui a probabilidade para o fim do projeto de ser, pois a existência só pode ser completa se possuir um início e um fim, na medida em que o homem determina seu projeto ele também está rumo a morte. Dessa forma, constitui uma liberdade-para-a-morte, em sua totalidade de livre escolha de seu fim. Ao passo que a morte é só mais um fenômeno humano, quando este vive bem sua vida, pois o término da construção do seu projeto de ser no mundo se dará na morte, momento este em que tudo se encerra, por não ter mais possibilidade de futuro.

No estudo do livro "A Cerimônia do Adeus" de Simone de Beauvoir (2012), no qual encontra-se os relatos dos últimos anos da vida de Sartre, a filósofa transcreve vários acontecimentos que mostram o caminho de finitude do projeto de ser, do pensador existencialista. Em seus escritos se pode 
acompanhar de forma minuciosa e experimentada, o impedimento de futuro que alcança a cada ser humano ao encontrar a morte.

Ainda sobre o livro, na trajetória histórica, os anos vão se passando, e gradativamente pode-se observar o definhar das forças físicas de Sartre. Com passar do tempo, sua saúde vai piorando, e o escritor vai tendo uma ideia de finitude de seu projeto. Sartre começa a vislumbrar a impossibilidade de futuro, passando do ser ativo, para uma pessoa que dependia de ajuda em quase todos os momentos, até mesmo em suas necessidade fisiológicas. Suas forças vão se consumindo como uma vela que se apaga aos poucos, e na consolidação de seu projeto, já não tem mais tantas possibilidades de futuro. Não relutava contra o inevitável, mesmo possuindo uma ardente vontade de realizar o projeto de ser, mas aceitava seu fim como algo necessário e comum a todos os seres. Ele sempre buscava novas formas de ver as possibilidades, e se adaptava as escolhas que podia fazer, mas mesmo assim escolhia em uma liberdade de ser, dentro de seus possíveis . Com isso a ideia da morte se tornara familiar e ele passou a aceitar sua chegada, mostrando-se sensível aos seus, e satisfeito com a totalização de seu projeto que se aproximava do fim.

Ao considerar toda temática apresentada que se inicia na tentativa de esclarecer o que é o projeto de ser, e que todo ser humano tem esse projeto terminado quando a sua vida chega ao fim, pois aí se encontra a impossibilidade de futuro. Com isso o estudo dos últimos anos de Sartre tem como objetivo possibilitar uma compreensão sobre a relação entre morte e o fim do projeto, almejando levantar uma discussão sobre os aspectos da morte e a finitude dos seres humanos e com isso tentar responder a seguinte questão de pesquisa. Segundo a Psicologia Fenomenológica Existencialista Sartreana, porque a morte é o fim do projeto de ser?

\section{MÉTODO}

Este artigo caracteriza-se como pesquisa exploratória, bibliográfica, assistemática, que segundo Gil (2002), a pesquisa bibliográfica se desenvolve a partir de produções já elaboradas, sendo constituída de artigos científicos e livros. A principal vantagem é conseguir investigar mais amplamente o fenômeno, pois em pesquisas que abrangem uma grande quantidade de pessoas ou com uma abrangência em maior nível se torna inviável outro método, bem como em pesquisas com dados históricos onde não há outro meio de conhecer os fatos passados.

O artigo se baseia em revisão de obras contidas nos seguintes livros publicados: O Ser e o Nada, O Ser e o Tempo, Sartre e a Psicologia Clínica, As Palavras, Introdução a Psicanalise Existencial, A Cerimônia do Adeus, Morte e o Desenvolvimento Humano, Esboço da Teoria das Emoções, Desenvolvimento Humano, O Existencialismo é um Humanismo, Como Elaborar Projetos de Pesquisa e Metodologia Científica e da Pesquisa, bem como em artigos periódicos indexados da base de dados do Scielo, BVS psi e teses. As buscas na base de dados foram realizadas com os seguintes termos de busca "ser para a morte", "projeto de ser", "tanatologia", "estudo sobre a morte", "fim do projeto de ser".

\section{O QUE É A ESCOLHA ORIGINAL E O PROJETO DE SER?}

Para Castro e Zanelli (2007), o homem está sempre em relação com o seu futuro, ou seja, a possibilidade de ser está sempre presente no processo de apropriação do mundo. Com isso todo homem tem um projeto em curso, tema central na psicologia existencialista, pois ao passo que se entende o projeto de ser do indivíduo, também se pode entender o processo de adoecimento do mesmo e/ou mediar mudanças em sua trajetória, e empenhar-se na busca uma saúde no desenvolver desse projeto rumo a sua totalização. Sendo que o projeto de ser, deve ser compreendido como uma livre eleição, uma escolha original, que o homem faz de si dentro de um quadro de possibilidades de escolhas, que se apresenta em sua vida, devido as condições sócio históricas. Fato que leva a 
compreensão que o homem é o seu projeto em um movimento continuo rumo a um vir-a-ser, constituído em um estado perpétuo de ser para além de si em direção a algo. Por isso pode se dizer que o homem é o seu futuro, para o qual ele se elege, ou seja, projeta-se determinando a algo em uma constante totalização em curso. Dizer que o homem é seu projeto, implica também entendê-lo dentro de seu contexto antropológico e sociológico, pois ali o mesmo passa ser livre em suas possibilidades de escolhas, em que vai se fazendo ser no mundo, se individualizando no meio as mediações na pluralidade dos seres. Com isso a existência passa a ser algo único e indissolúvel, pois a medida que o indivíduo se elege e lança-se ao mundo, o mesmo vai organizando seu projeto dentro de suas condições particulares.

Em seus estudos Ehrlich (2002) busca um entendimento do projeto de ser de cada indivíduo, como uma ação que o leva a um mundo futuro e desejável a ser alcançado, mas ainda inexistente. Podendo afirmar que nenhuma ação é gratuita ou desnecessária, mas cada ação feita por cada indivíduo implica diretamente em seu futuro, nada é por acaso, nada é inconsciente, mas tudo é intencional rumo a um futuro, sem existir algo predestinado, mas algo projetado através de escolhas definidas nas ações cotidianas. Ao passo que o homem se faz nas escolhas, em uma livre unificação. Ele decide o seu futuro projetando-se por seus atos, mas tais escolhas podem estar envoltas em emoções produzindo a incompreensão dos objetivos projetados para seu futuro.

Para Castro e Ehrlich (2016), toda e qualquer ação do ser humano no mundo não se reduz a impulsos cegos, inconscientes como se fosse um saber que não se sabe. Portanto, toda e qualquer escolha leva a uma ação que vai se constituindo em um projeto de ser, sempre em construção, e que se estabelece a partir de uma escolha original. As escolhas vão dando forma ao projeto, e a existência se faz sempre rumo a uma totalização em curso, em um princípio individualizante de cada ser, marcado pelo processo totalizante da historicidade, demarcada em um horizonte temporal de um projeto de ser, com isso a escolha original leva a ações singulares que unifica sua existência no mundo. Pode-se afirmar então que o projeto de ser é algo concreto, imerso em meio as coisas do mundo, transcendendo rumo a um futuro desejado. Cada ser é um corpo sensível em movimento em meio a materialidade do mundo, que se experimenta cercado pelas coisas e pelos outros, lançando-se a uma condição futura não existente. Ou seja, o projeto de ser é uma totalização em curso fundada em uma escolha original, logo nenhuma escolha, ação ou experiência vivida se reduz nela mesma, mas se une articulando o projeto de ser, constituindo alguém singular formado em um conjunto de todas as experimentações vividas no mundo.

\footnotetext{
Neste sentido, a realidade humana, ao ser uma totalização que se elege perpetuamente elegendo o mundo no qual se objetiva, está impossibilitada de agir a-historicamente. Se me dedico quotidianamente ao estudo de determinadas obras literárias, é certa totalização de uma escolha original relativa à intelectualidade que realizo, é um mundo cercado por objetos intelectualmente significativos que produzo, são pessoas ligadas a literatura com as quais me envolvo e é um certo mundo futuro vinculado à intelectualidade em direção ao qual me movimento. É um ser em um mundo que se fazem correlativamente na ação de passar os dias no trabalho literário. O desenvolvimento histórico dessa escolha original não se expõe tanto ao sol, nem se exercita fisicamente, por exemplo. (CASTRO; EHRLICH, 2016, p. 86)
}

Schneider (2011) apresenta uma reflexão sobre o projeto de ser, dizendo que ele se caracteriza na busca de todo ser humano, em realizar-se plenamente em seu existir. Visto que uma vez lançado ao mundo, todo indivíduo se encontra em uma direção ao futuro, sempre em direção a algo em uma totalização em curso. Portanto, não há como existir um humano sem um projeto, pois mesmo não ter projeto já é um projeto, da mesma forma que não escolher nada já se constitui em uma escolha. Pois quando o sujeito é lançado ao mundo este segue em direção a um fim mesmo não tendo clareza de qual ele é, e quando vai acabar. 


\begin{abstract}
Nosso ser está imediatamente "em situação", ou seja, surge no meio dessas atividades e se conhece primeiramente na medida em que nelas se reflete. Descobrimo-nos, pois, em um mundo povoado de exigências, no seio de projetos "em curso de realização": escrevo, vou fumar, tenho encontro com Pedro esta noite, não devo esquecer de responder a Simão, não tenho direito de esconder a verdade de Cláudio por mais tempo. Todas essas pequenas esperas passivas pelo real, todos esses valores banais e cotidianos tiram seu sentido, na verdade, de um projeto inicial meu, especie de eleição que faço de mim mesmo no mundo (SARTRE, 2015, p. 83).
\end{abstract}

Em cada movimento desse sujeito no mundo, existe uma significação que o transcende. Sendo assim, em cada escolha concreta aparece a realização do projeto de ser, cada ato ou escolha se constitui como escolha fundamental, com isso as escolhas cotidianas definem o sujeito, que por sua vez lançam o sujeito na ação, nas complicações e nas atitudes, essas escolhas dão forma ao ser do indivíduo. Podendo dizer assim que: "o homem se constitui dessa forma, em uma livre unificação das diversas escolhas empíricas em direção a um projeto fundamental. O projeto se caracteriza assim pela totalização em curso que é o homem". (SCHNEIDER, 2011, p. 128).

Para Sartre (2015) no que diz respeito ao projeto fundamental compreende-se que deve ser concebido por si próprio, sem se remeter a nenhum outro, pois o projeto original é um Para-si, isso é, a consciência que se defronta com o mundo em um processo dialético que só pode visar seu próprio ser, sendo assim, o projeto de ser não provem de uma definição fisiológica nem uma contingência empírica. Com isso o Para-si é um ser cujo o ser, está em questão em seu ser, e em forma de projeto de ser percorrido no caminho das possibilidades, trilhados sob os signos de valores possíveis e valores pertencem a consciência que se defronta com as experiências na ação no mundo, pois o Para-si, define ontologicamente como falta de ser e o possível é o que falta ao ser, aquilo que ainda não é. Ao passo que o valor, impregna a totalidade de ser faltada e pode se exprimir como liberdade, visto que o Para-si escolhe para preencher a falta, o vazio existente em seu ser.

O Para-si escolhe por que é falta; a liberdade identifica-se com a falta, pois é o modo de ser concreto da falta de ser. Ontologicamente, por conseguinte, tanto faz dizer que o valor e o possível existem como limites internos de uma falta de ser que só poderia existir enquanto falta de ser - ou que a liberdade, ao surgir, determina seu possível e, com isso, circunscreve seu valor. Assim, não podemos remontar-nos mais além, e encontramos o irredutível evidente ao atingir o projeto de ser, pois, evidentemente, é impossível remontarse mais além do ser, e não há diferença alguma entre projeto de ser, possível e valor, de um lado, e ser, de outro. O homem é fundamentalmente desejo de ser, e a existência desse desejo não deve ser estabelecida por uma indução empírica; resulta de uma descrição a priori do ser do Para-si, posto que o desejo é falta, e o Para-si o ser que é para si mesmo uma de nossas tendências empiricamente observáveis consiste, portanto, no projeto de ser; ou, se preferirmos, cada tendência empírica existe com o projeto original de ser em uma relação de expressão e satisfação simbólica (SARTRE, 2015, p. 692).

Para compreender melhor se pode dizer que o projeto se dá na concretização do desejo de ser, tendo em vista que todo ser humano se realiza em seu projeto fundamental, envolto em escolhas originais, nesse desejo de ser que o puxa, movendo-o no mundo, com suas características particulares, sendo combustível para a dinâmica psicológica que constitui o sujeito no mundo. Ao lançar-se ao mundo o ser humano define a cada passo seu existir, impulsionado a vivenciar todas as experiências destinadas a existência. Constitui-se dessa forma um ser para a morte (SARTRE, 2015).

\title{
4 O SER PARA MORTE
}

Conforme Heidegger (2005), a morte é uma possibilidade ontológica singular onde ninguém pode morrer por outro, mas cada um faz sua experiência particular no processo de finitude. Se essa 
experiência é particular e alcança a totalidade dos indivíduos, aparece aí o ser para a morte, pois esse fenômeno alcança a todos. Findar não quer dizer essencialmente completar-se, mas chegar a impossibilidade de continuar uma existência. Em um sentido mais amplo morte é um fenômeno da vida e por isso deve ser considerado como parte integrante de uma totalidade do ser no mundo. Com isso a morte é a possibilidade mais própria do ser-no-mundo, apresentando-se de forma irremissível, insuperável e inevitável ao curso do existir. A partir do momento que cada ser é lançado ao mundo, essa possibilidade passa a ser uma verdade que acompanha em todo o processo de se fazer no mundo.

Da mesma forma que a pre-sença, enquanto é, continuamente já é seu ainda-não, ela também já é seu fim. O findar implicado na morte não significa o ser estar-no-fim da pre-sença, mas o ser-para-o-fim. A morte é o modo que pre-sença assume no momento em que é. Para morrer basta estar vivo (HEIDEGGER, 2005, p. 26).

Nesse sentido o ser para a morte não é algo que as vezes acontece. Pois o ser no mundo assume a possibilidade de não estar mais aí no momento seguinte. Com isso pode se pensar que para morrer basta estar vivo, fato singular que só há morte, se tiver vida e da mesma forma só há vida porque existe a morte como completude do existir (HEIDEGGER, 2005).

Para Rothschild e Calazans (2008), a todo momento o ser humano é impelido a escolher e cada escolha aponta para o futuro que o puxa, pois todo projeto aponta para um futuro que ainda não é, mas poderá vir a ser, como também tem a possibilidade de não ser, uma vez que se implica nas possibilidades de também não estar mais aí. Com isso a morte passa a ser um fenômeno cotidiano, sendo ela a possibilidade mais peculiar, irrefutável, tida como certeza única, pois a partir do momento que o ser humano é lançado ao mundo, ele se encontra envolto de todas as infinitas possibilidades que constitui o homem em seu projeto, e ao mesmo tempo, desde seu nascimento, já se encontra presente a absoluta impossibilidade de não estar mais aí. Aniquila assim toda e qualquer possibilidade de seguir e transcender seu projeto de ser.

Segundo Castro e Ehrlich (2016) a morte na visão existencialista sartreana não constitui como um fim originário como primeiramente pensava Heidegger, pois para Sartre a morte se apresenta como uma dimensão fatídica do existir, ou seja, ela é um impedimento da totalização em curso de um projeto de ser. Com isso se pode pensar que todo acontecimento que extingue uma possibilidade de vir a ser, que elimina qualquer vínculo com o futuro, esse acontecimento é a morte, acontecimento brutal que interrompe o seguir livre de um projeto de ser, pois anula qualquer possibilidade de transcender, não permitindo ao ser uma significação de suas escolhas originarias, pois aborta qualquer sentido de um vir a ser. Sendo assim a morte é a aniquilação de todas as possibilidades de escolhas, pois extingue toda a transcendência possível ao ser humano.

Para Sartre (2015) a morte tem a característica de individualizar o ser humano, pois é um fenômeno da vida pessoal que o torna único, em que o indivíduo passa a ser responsável tanto pela vida como pela morte, não pelo fenômeno contingente, mas pelo caráter de finitude. Porém a morte não pode ser uma escolha, por ser um impedimento da continuidade do projeto de ser, e não pode ser concebida como possibilidade, mas ao contrário ela é uma nadificação de toda e qualquer possibilidade, ou seja, ela não aparece como fundamento da liberdade dentro do existir, mas sim o fenômeno que tira a liberdade de escolha, pois aniquila o futuro anulando a possibilidade da transcendência das significações originarias, com isso, ela é a extinção do existir o impedimento no transcender de se fazer essência.

Sendo assim, poder-se-ia pensar no suicídio como uma possibilidade de término pela escolha, mas para Castro e Ehrlich (2016) o suicídio ainda é um absurdo da facticidade dentro do existir, pois nada mais é que uma saída desesperada na busca de solucionar um impasse, relacionado a um por vir, mas se a vida se faz na transcendência das possibilidades o suicídio é apenas a saída encontrada diante do sofrimento humano que se complica na trajetória do seu projeto de ser. Mas não pode ser 
considerado um projeto visto que se torna um impedimento da existência do ser no mundo, portanto não há lugar para a morte dentro do projeto de ser.

Assim, devemos concluir, contra Heidegger, que a morte, longe de ser minha possibilidade própria, é um fato contingente que, enquanto tal, escapa-me por princípio e pertence originariamente à minha facticidade. Eu não poderia descobrir minha morte, nem esperá-la, nem tomar uma atitude com relação a ela, visto ser aquilo que se revela como o irrevelável, aquilo que desarma todas as esperas e que penetra em todas as atitudes. (SARTRE, 2015, p. 668)

Segundo Sartre (2015), a morte passou a ser vista como algo inumano por excelência, ou seja, sempre olhada a distância como se não fosse um acontecimento humano. Para ele a morte tem sido considerada como aquilo que ainda não se pode determinar, acontecimento esse que escapa ao homem ficando fora do seu alcance, e se molda em formato não humano, porém, o fato de cada indivíduo ser inteiramente humano, a completude de seu existir se dará no ato final, fazendo a experiência vital da morte. Sendo que essa experiência da morte passa a ser o fenômeno último da vida, fenômeno esse que faz da vida do ser humano algo único sem possibilidade de uma segunda chance, com isso a morte se converte no sentido da vida, pois o fenômeno da vida do indivíduo é algo que só ele pode viver, é o que faz com que a vida de cada ser humano seja única, dessa forma ele se torna responsável por sua morte tanto quanto por sua vida. Assim, a morte passa a ser uma facticidade do próprio ser no mundo, com sua realidade humana, que vai se definindo como um ser que caminha para um fim. Visto que ao lançar-se rumo ao seu projeto-de-ser o homem também segue rumo a morte, quando qualquer acontecimento venha a impedir as possibilidades de escolha.

Conforme Kübler-Ross (2008), o ser humano passa a se defender de vários modos dos seus medos, criando uma angústia crescente, da possibilidade da morte e a incapacidade de poder prevê-la, e passa a criar mecanismos de defesas psicológicos, que o levam a negar a existência da morte, gerando assim uma ideia que ultrapassa a realidade humana, e dessa forma se engana em um pensamento de imortalidade. Algo que não proporciona discutir ou pensar a morte como parte integrante da existência humana, sendo assim o fenômeno da morte passa a assumir um pensamento errado, a sociedade passa a encarar a morte como acontecimento fora da naturalidade humana, algo impronunciável do qual não se faz necessário pensar, se esquecendo que "a morte é um fenômeno humano, fenômeno último da vida, mas ainda assim vida" (SARTRE, 2015, p. 652).

Para Sartre (1967), a morte torna o homem objeto por não haver mais relação, não existir mais possibilidade de futuro, pois restará somente o passado, que coisifica o defunto, que fica no meio do caminho entre o ser e o valor, torna-se um em-si impedido de haver qualquer possibilidade de se relacionar com as coisas no mundo, sendo um impedimento de caráter absurdo imposto pela facticidade temporal. Sendo assim não há como prever a chegada do momento que findará o curso do projeto de ser. Uma vez que não se sabe quem vive ou morre, seria possível mensurar quanto tempo tem o ser para se viabilizar em sua construção de projeto? Não é possível saber, qual o fim, mas é possível pensar e refletir que toda a existência tem um fim. "Você nunca pensou ao escovar os dentes: desta vez tá aí, é o meu último dia? Você nunca sentiu que era preciso andar depressa, depressa, muito depressa, que o tempo era curto? Você se julga imortal?" (SARTRE, 1967, p. 125).

Segundo Kovács (2014), nos dias atuais, essa compreensão de interdição da morte, leva a querer evitá-la a qualquer preço, gerando uma ideia de seres imortais, esse pensamento, pode-se dizer que está diretamente ligado aos avanços tecnológicos da medicina e dos profissionais que atuam na área da saúde. Fato que faz com que a maioria das mortes por doenças graves venham acontecer nos hospitais, em um ambiente solitário, distante da realidade que o sujeito vive, pois se busca manter a vida a qualquer preço e a perda de um indivíduo nesses locais é vista como falha ou fracasso no tratamento. Por outro lado, os que sobrevivem são vistos como heróis, logo o que morreu se torna um perdedor. 
Conforme Papalia e Feldman (2013), o fenômeno da morte não se trata apenas de um fenômeno biológico, mas apresenta aspectos que vão além, pois se apresenta para cada ser humano de uma forma particular, sendo que o mesmo está imerso em uma cultura, de uma determinada sociedade, vivendo um determinado tempo histórico, com suas complicações psicológicas. Para compreender o processo da morte como fim do projeto do ser, algo natural a todo indivíduo, busca-se na trajetória histórica de Jean-Paul Sartre em meio aos relatos de suas escolhas até o fim de sua vida, contribuir para esse processo de entendimento do projeto de ser e sua finitude.

\section{SARTRE, E AS ESCOLHAS ORIGINAIS}

No livro As Palavras escrito por Jean-Paul Sartre (1967), percebe-se a construção do projeto de ser do escritor existencialista na narrativa de sua história. Nesse livro, Sartre vai se definir em cada uma de suas escolhas e se projetar rumo ao futuro, que vai se configurar a partir da escolha original. Por ter perdido o pai ainda criança, fica aos cuidados da mãe e avós maternos. Seu avô tem um papel importante como mediador no processo de apropriação do mundo e constituição de ser de Sartre. A sociedade francesa da época estava com o orgulho ferido e isso viria a ser importante na construção de seu projeto, pois ele vai se ver como criança francesa nos heróis, esses heróis imaginários servem para contrabalancear o sentimento francês que estava ferido. A configuração familiar, dentro da sociedade francesa da época, irá influenciar no contexto antropológico e sociológico, e proporcionar as condições necessárias para a definição de seu projeto de ser escritor, em meio a uma materialidade é que ele se faz ser no mundo em meio aos livros na biblioteca do avô.

As experiências empíricas das escolhas na vida do escritor existencialista, vão acontecer no seio familiar que se apresenta em um contexto dentro de uma sociedade em um determinado tempo, conforme aponta Schneider (2011) todo ser humano é um ser social por excelência, por se encontrar dentro de um determinado território que também irá influenciar a construção do projeto de ser, uma vez que fornece horizonte de parâmetros para se constituir a singularidade do indivíduo, que está envolto nas práticas sociais com os valores, conhecimentos e ideologias que o ambiente lhe proporciona como possibilidade de escolhas. Essa contribuição sociológica passa pelo processo de mediação, ou seja, as pessoas e as coisas mais perto da criança realizam uma espécie de intersecção de valores sociais, culturais, com seus signos que irá dar significado as necessidades do sujeito, que vai se desenvolve no processo de socialização, assim ele se faz pessoa no seio da sociedade, nutrida pelo conhecimento, crenças e valores que se apresentam no contexto antropológico e sociológico.

Comecei minha vida como hei de acabá-la, sem dúvida: no meio dos livros. No escritório de meu avô, havia-os por toda parte; era proibido espaná-los exceto uma vez por ano antes do reinicio das aulas em outubro. Eu ainda não sabia ler e já reverenciava essas pedras erigidas: em pé ou inclinadas, apertadas como tijolos nas prateleiras da biblioteca ou nobremente espacejadas em aléias de menires, eu sentia que a prosperidade de nossa família delas dependia. Elas se pareciam todas; eu foliava num minúsculo santuário, circundado de monumentos atarracados, antigos, que me haviam visto nascer, que me veriam morrer e cuja permanência me garantia um futuro tão calmo como o passado. Eu os tocava às escondidas para honrar minhas mãos com sua poeira, mas não sabia bem o que fazer com eles e assistia todos os dias a cerimônias cujo sentido me escapava. (SARTRE, 1967, p. 26)

Nessa citação se encontra um princípio que irá nortear toda a vida do escritor existencialista, sendo possível observar o movimento que ele faz no mundo em meio as coisas, segundo seu quadro de escolhas, lançando-se a escolher segundo sua cultura e suas mediações. Fato anteriormente abordado na construção do projeto de ser, referenciado por Castro e Ehrlich (2016) que trazem o entendimento que todas as ações que se realizam no mundo em meio as coisas, se totalizam a partir de escolhas 
originais, visto que a realidade do ser que vai se viabiliza no mundo está diretamente ligada a ação que ele se lança no mundo. Ou seja, todas as ações e experiências vividas são partes integrantes de uma totalização em curso fundamentada por uma escolha original, toda ação, toda a experimentação do ser no mundo está diretamente ligada no interior de uma história singular, que se projeta a um futuro porvir rumo a algo a ser alcançado, e se torna a totalização em curso das escolhas originais possíveis a cada ser humano segundo sua possibilidade de escolhas.

As densas lembranças, e a doce sem-razão das crianças do campo, em vão procurá-lasia, eu, em mim. Nunca esgaravatei a terra nem farejei ninhos, não herborizei nem joguei pedras nos passarinhos. Mas os livros foram meus passarinhos e meus ninhos, meu animais domésticos, meu estábulo e meu campo; a biblioteca era o mundo colhido num espelho; tinha a sua espessura infinita, a sua variedade e a sua imprevisibilidade. Eu me lançava a incríveis aventuras: era preciso escalar as cadeiras, as mesas, com o risco de provocar avalanches que me teriam sepultado (SARTRE, 1967, p. 31).

Ao colocar a vida de Sartre dentro de sua teoria é preciso observar o que fala Schneider (2011) sobre as dimensões antropológicas, uma vez que esse se encontra em meio a uma realidade histórica permeada por saberes inerentes a seu tempo e imerso em uma cultura familiar que proporciona um certo tipo de mediação em que cada um é um meio para o outro realizar seu projeto, dependendo do outro para ser quem se quer ser; "Até os dez anos, fiquei só entre um velho e duas mulheres. Minha verdade, meu caráter e meu nome estavam nas mãos dos adultos; aprendera a ver-me com os olhos deles; eu era uma criança, esse monstro que eles fabricam com suas queixas" (SARTRE, 1967, p. 53). Para a psicologia existencialista, a mediação familiar tem importância fundamental na construção do projeto de ser, visto que ali está posto as primeiras mediações que delinearam os princípios de apropriação do mundo. "a noção de mediação é fundamental para compreender a realidade humana. Somos meios uns para os outros para realizar nosso ser; sem as mediações sociais não nos humanizaríamos não superaríamos a condição de animais" (SCHNEIDER, 2011 p. 153).

Em tais condições, o escritor existencialista se vê em um papel de coadjuvante, não de protagonista de suas histórias. Estava condenado a agradar, desempenhando um falso-bom-papel, mas sem uma cena própria desejava um protagonismo, porém continuava abstrato, sem alma sentindo-se transformar em um objeto sob os olhares dos outros.

Alguém poderá pensar que eu era muito presunçoso. Não: eu era órfão de pai. Filho de ninguém, fui minha própria causa, cúmulo de orgulho e cúmulo de miséria; eu fora posto no mundo pelo impulso que me levava para o bem. O encadeamento parece claro: feminizado pela ternura materna, desenxabido pela ausência do rude Moisés que me engendrara, enfatuado pela adoração de meu avô, eu era puro objeto, devotado por excelência ao masoquismo se apenas eu tivesse conseguido acreditar na comédia familial (SARTRE, 1967, p. 72).

Para Schneider (2011), a essência não é algo nato, mas que precisa ser construída. Portanto passa por um processo histórico de totalização na relação do sujeito, mediada pelo sociológico e antropológico, assim todas as escolhas vão se unificando e formando a personalidade. Pois é necessário a apropriação do mundo para ser alguém, tendo aqui a máxima existencialista, onde a existência precede a essência, ou seja, primeiro o ser é lançado ao mundo no qual estabelece relação para então se personalizar. O que pode ser visto nos relatos de Sartre aos sete anos em que ele se apropria de sua existência e do transcender de seu ser, na direção de se ver com seus próprios olhos, "Nasci para satisfazer a grande necessidade que eu tinha de mim mesmo; conhecera até então apenas as vaidades de um cão de luxo; 
acuado no orgulho, tornei-me o Orgulhoso. Já que ninguém me reivindicava, levantei a pretensão de ser indispensável ao universo" (SARTRE, 1967, p. 71).

\begin{abstract}
Mais tarde, ousei retocá-las, atribuir-me nelas um papel. Mudaram de natureza; eu não gostava das fadas, havia demasiadas à minha volta: as façanhas substituíram a feérie. Torneime um herói; renunciei a meus encantos; não se tratava mais de agradar, porém de se impor. Abandonei minha família: Karlemami, Anne-Marie foram excluídos de minhas fantasias. Farto de gestos e atitudes, realizei verdadeiros atos em sonhos (SARTRE, 1967, p. 72).
\end{abstract}

Segundo Sartre (1967), a sua realidade de escolhas transitava entre o saber e o objeto, e se achava mais na ideia que na realidade das coisas. Em meio aos livros se constituía como ser no mundo, em um universo do qual ele se apropriou nas experiências livrescas, como um curso aventuroso dos acontecimentos reais. A escrita e os livros se tornavam objetos de sua devoção "Eu achara a minha religião: nada me parece mais importante do que um livro. Na biblioteca, eu via um templo. Neto de sacerdote, vivia sobre o telhado do mundo" (SARTRE, 1967, p. 38).

Seu mundo se tornara a literatura e imerso nas páginas se projetava em meio a um quadro de escolha possíveis, se lançava rumo ao seu projeto, tomando as palavras como a quinta essência das coisas. Sua escrita se tornara tudo, escrevia para alimentar seu prazer. Com isso se descobre e dá sentido à sua existência, se torna herói no enredo romântico de suas histórias, e se experimenta em cada linha como ser escritor (SARTRE, 1967).

Eu começava a descobrir-me. Eu não era quase nada, quando muito uma atividade sem conteúdo, mas não era preciso mais. Eu escapava à comédia: não trabalhava ainda, porém não brincava mais, o mentiroso encontrava sua verdade na elaboração de suas mentiras. Eu nasci da escrita: antes dela, havia tão-sòmente um jôgo de espelhos; desde o meu primeiro romance, soube que uma criança se introduzira no palácio dos espelhos. Escrevendo, eu existia, escapava aos adultos: mas eu só existia para escrever, e se eu dizia eu, isso significava: eu que escrevo (SARTRE, 1967, p. 96).

No trecho acima encontra-se os relatos da apropriação de Sartre do mundo que o cercava e a elaboração de suas escolhas, agora como protagonista de sua história e fundamentando sua essência. Conforme Schneider (2011), as escolhas originais que demarcam a existência em um projeto de ser são parte fundamental do psiquismo humano, são as experimentações psicofísicas do homem imerso no mundo, indicativos da construção de sua personalidade, pois toda a ação é um fenômeno da consciência, e consciência é sempre consciência de alguma coisa, sendo uma pura relação com o mundo. Com isso toda a relação com a materialidade do mundo que cotidianamente vai se apresentando a cada pessoa, vai dando forma ao sujeito quando esse apropriar-se das coisas nas ações levadas por escolhas, sendo assim cada escolha é um fenômeno de transformação do mundo.

Conforme Sartre (2014), a máxima existencialista que o homem é aquilo que faz de si mesmo, isso pode ser chamado de Cógito, Eu no mundo, por isso antes de mais nada o homem existe, para posteriormente construir sua essência, que o faz ao se projetar em um futuro, e esse tem a consciência de se projetar rumo a um por vir. O que fica claro nas experiências do próprio escritor "Eu não podia admitir que a gente recebesse o ser de fora, que ele se conservasse por inércia, nem que os movimentos da alma fossem os efeitos dos movimentos anteriores. Nascido de uma expectativa futura, eu saltava, luminoso" (SARTRE, 1967, p. 150).

eu queria ver nas afecções de meu coração um crepitar de fagulhas. Por que, pois, haveria o passado de me enriquecer? Ele não me fizera; era eu, ao contrário, ressuscitando de minhas cinzas, que arrancava do nada minha memória através de uma criação sempre recomeçada. Eu renascia melhor e utilizava melhor as inertes reservas de minha alma pela simples razão de que a morte, cada vez mais próxima, me iluminava mais vivamente com sua obscura luz. 
Diziam-me amiúde: o passado nos impele; mas eu estava convencido de que o futuro me puxava; eu teria detestado sentir em mim forças mansas em ação, o lento desabrochar de minhas disposições (SARTRE, 1967, p. 150).

Conforme o entendimento existencialista Sartre se faz em um progresso contínuo, em um transcender nas ações diárias, e mesmo ao se aproximar do fim de sua vida, ele não olhava o passado como uma força, mas estava convicto que o futuro o puxava e isso era motor que o movia a escolher. Mesmo com sua saúde precária, seu corpo envelhecido, ele continuava sendo um amante da vida. Projetando-se a um futuro, o pensador existencialista vai caminhando para sua cerimônia do adeus. "Aprendi a suportar as aflições e as moléstias; vi nelas as primícias de minha morte triunfal, os degraus que esta talhava para me elevar até ela[...] Cego ou estropiado, transviado por meus erros, ganharia a guerra à força de perder as batalhas" (SARTRE, 1967, p. 148).

\section{A CERIMÔNIA DO ADEUS}

Em meio aos livros o projeto de Sartre vai se constituindo, o escritor se encontra imerso no mundo em meio a materialidade vivendo a realidade de suas experimentações, seu existir se constituía nesse ambiente de escrita e leituras, fato que proporcionava uma influência na sociedade da época, devido ao sucesso de suas obras, a força contida em suas palavras, e o seu pensamento filosófico. Tudo isso dará ritmo na linha de pensamento de uma geração não só na França, mas com alcance mundial, tornando o escritor existencialista um destaque tanto no meio literário, quanto na política e nas transformações do seu tempo. Conforme o tempo ia passando e sua trajetória chegava ao fim, percebe-se a realização de seus projetos contidas em suas palavras, "comecei minha vida como hei de acabar, sem dúvida em meio aos livros" (SARTRE, 1967, p. 26).

Na leitura do livro A cerimônia do adeus, pode se encontrar os relatos dos últimos anos da vida de Sartre, descritos por Simone de Beauvoir. A trajetória desses relatos biográficos, são ricos de detalhes, mostrando a intensa cumplicidade dos escritores, bem como a cerimônia de despedida que dura uma década até o encerramento do projeto de ser de Sartre. O conteúdo do livro mostra todo processo de escolha e espera de Sartre no caminho de sua finitude, assim como a participação intensa de Simone em todo esse caminho de liberdade e entendimento da realidade inerente da morte.

\footnotetext{
Eis aqui meu primeiro livro - o único certamente - que você não leu antes que o imprimissem. Embora todo dedicado a você, ele já não lhe concerne. Quando éramos jovens e, ao final de uma discussão apaixonada um de nós triunfava ostensivamente, dizia ao outro: "Você está enclausurado!" Você está enclausurado; não sairá daí e eu não me juntarei a você: mesmo que me enterrem ao seu lado, de suas cinas para meus restos não haverá nenhuma passagem. Este você que emprego é um engodo, um artifício retórico. Ninguém me ouve; não falo com ninguém. Na realidade, dirijo-me aos amigos de Sartre: àqueles que desejam conhecer melhor seus últimos anos. Relatei-os tal como os vivi. Falei um pouco de mim, porque a testemunha faz parte de seu testemunho, mas fiz isso o menos possível (BEAUVOIR, 2012, p.13).
}

Conforme Beauvoir (2012), a década que se inicia em 1970, Sartre começa a trilhar mais estreitamente seu caminho para a finitude. No início da leitura se pode observar Sartre em plena realização de seu projeto, ativo em meio aos desafios de seu tempo, atuante na sociedade, se totalizando em suas escolhas. Durante sua existência não deixava de pensar sobre seus interesses ideológicos e não queria que o alienassem. Por isso estava sempre em busca de seus ideais, lutando pelo povo como intelectual, deixando de lado o intelectual clássico para o surgimento de um novo intelectual. "O novo intelectual procura fundir-se com a massa, para fazer triunfar a verdadeira universalidade"(BEAUVOIR, 2012, 
p. 15). Com isso se pode ver a intensa atividade física e intelectual contida na força vital que se lança ao mundo na ação que constitui seu projeto de ser.

Para Schneider (2011), a psicologia existencialista deve entender o sujeito e suas ações no mundo, o mesmo deve ser compreendido como um ser em situação ao mesmo tempo que é singular também é universal, que se faz em uma rede interligada de várias experimentações, gostos, emoções, tudo contribui para entendimento do projeto de ser. Sendo assim, ao acompanhar a narrativa de Simone de Beauvoir é possível encontrar as experimentações de Sartre vividas no decorrer de seus dias, em que se experimenta no envelhecimento, e com ele todas as dificuldades psicofísicas que se apresentam nesse período da vida, transcritas ao olhar dela "Como vai? perguntei-lhe de maneira rotineira. "Pois é Não muito bem." De fato, vacilava, balbuciava, tinha a boca um pouco torta. Na véspera, eu não percebera que ele estava fatigado" (BEAUVOIR, 2012, p. 33).

Conforme Beauvoir (2012), sua saúde começa a dar sinais de esgotamento, após beber muita vodca, e ter que ser ajudado a ir para o quarto, no dia seguinte quando Simone vai buscá-lo para almoçar ele não estáva bem esbarrava nos móveis, cambaleava como se estivesse bebido muito, ao descer do carro quase caiu. Já fazia tempo que se preocupava com a saúde de Sartre, ao vê-lo em mau estado acometido por um pequeno derrame, ela tenta manter-se a sangue-frio, pensando em amigos que passaram por isso e saíram ilesos, mas lutava contra a angústia, pois tinha noção da situação.

\begin{abstract}
No final de junho, Sartre começou a sentir dores atrozes na língua. Não conseguia comer, nem falar sem sofrer. Eu lhe disse: "O ano está mesmo péssimo: o tempo todo você teve problemas." "Oh! isso não tem importância", respondeu ele. "quando se está velho, isso já não tem importância." "Como assim?" "Sabe-se que isso já não vai durar muito tempo." "Está querendo dizer, porque se vai morrer?" "Sim. É normal que se vá decaindo pouco a pouco. Quando se é jovem, é diferente." O tom com que disse isso me perturbou: parecia já do outro lado da vida. Aliás, todo mundo notava esse desapego; ele parecia indiferente a muitas coisas, certamente porque estava desinteressado por seu próprio destino. Muitas vezes mostrava-se, se não triste, pelo menos ausente" (BEAUVOIR, 2012, p. 37).
\end{abstract}

Nessa fala se pode acompanhar o escritor em uma nova etapa de experimentações, mas ao mesmo tempo um entendimento da realidade que se apresenta nas situações vividas, o que para Castro e Ehrlich (2016) demostra a realidade humana que vai transcendendo para um futuro e temporalizando-se, a morte é uma interrupção desse processo, pois ela faz cessar toda a ação no mundo, com isso, não há lugar para ela dentro de um projeto de ser, pois o projeto não se esgota ele transcende nas escolhas, mas inevitavelmente a morte é a facticidade que encerra toda a transcendência, sendo assim, a morte não pode ser uma possibilidade própria, pois ela é em si uma impossibilidade do sujeito no mundo.

Ao mesmo tempo que sua vida se constitui em escolhas, a sua finitude não deixa de ser pensada como algo possível. Sartre tinha clareza de suas condições, pensava na morte como certeza inevitável e próxima, se preparando na liberdade de escolher, dentro de seus projetos, não ignorando, mas esperado sua terminalidade.

E falou-me de seu enterro. Desejava uma cerimônia muito simples e desejava ser cremado. Sobretudo, não queria ser colocado no PèreLachaise entre sua mãe e seu padrasto. Desejava que grande número de maoístas acompanhasse seu caixão. Não pensava nisso com frequência - disse-me -, mas pensava (BEAUVOIR, 2012, p. 39).

Aqui Sartre dá indícios de como gostaria que procedessem em sua morte, deixando como que um testamento para hora da morte. Ele está olhando para a sua própria morte falando de seus sentimentos e expressando o que passa na experimentação das situações vividas, não olha de fora como 
se fosse de outro, mas faz uma reflexão das coisas empíricas vividas, relatando seu desejo bem como expondo como gostaria que fossem os procedimentos após sua morte. Conforme Silva (2014), há uma grande necessidade de criar discussões científicas sobre a terminalidade da vida. Sobre tudo que esses estudos busquem se col e avanço, gerando um sentimento de derrota ou impotência. Fato que torna a abordagem do assunto morte ou morrer, terem grandes desafios para serem amplamente dialogado com a sociedade. Ocorre também a urgência em sair do meio acadêmico no campo de discussão e ser colocado em prática pelos profissionais que atuam na área de saúde e educação, buscando sempre uma atuação mais humanista nas intervenções e estudos (SILVA, 2014).

A morte é vista como parte fundamental da existência, por isso pode ser planejada ou pensada anteriormente, discutida podendo ser levada a um planejamento de fim de existência, deixando como que um testamento para a hora da morte, falando abertamente como proceder anteriormente e no desfecho final. Visto que os cuidados finais devem estar cercados de solidariedade, compaixão, sem pensamentos autoritários ou paternalistas, que não contribuem para uma boa morte. "Os pacientes que puderam falar com seus médicos sobre o fim da vida tiveram maior probabilidade de morrer em paz e ter controle da situação." Morrer com qualidade deve promover discussões em torno da autonomia do indivíduo em como se dará seu fim. Com isso os cuidados paliativos têm essa finalidade de ser suporte para o paciente na hora da morte e morte com dignidade buscando facilitar sua autonomia sobre algo que diz respeito a uma parte integrante de seu existir (KOVÁCS, 2014).

Quanto mais passava a realidade cronológica, mais se adquiria a consciência da degradação da velhice, algo irreversível. Sartre estava com incontinência urinária ao passo de não conseguir mais se conter, mas ele tratava isso como naturalidade da idade em que estava, ele sempre se mostrou muito discreto e jamais aludia a suas necessidades fisiológicas, passara ele a demostrar sempre, uma apatia em relação ao seu corpo e as coisas, algo que começa a mexer com Simone, ao que ela o questiona. "Por isso, perguntei-lhe, no dia seguinte pela manhã, se essa falta de controle não o constrangia. Ele me respondeu, sorrindo: "É preciso ser modesto, quando se é velho" (BEAUVOIR, 2012, p. 54). O fato a deixava emocionada, por sua simplicidade, mas ao mesmo tempo triste por parecer não lutar mais com tanta força.

Esse entendimento que Sartre tem de sua velhice está ligado diretamente ao ser temporal, que também é finito, pois ao lançar-se no futuro, não é possível parar ou voltar ao tempo passado, pois não há como regressar, mas somente escolher dentro daquilo que o tempo cronológico apresenta, que é sempre de uma forma irreversível, sendo que o processo temporal torna finito os projetos humanos. Sendo assim com uma impossibilidade de voltar no tempo ou alterar o passado o mais sensato é se adaptar à realidade que se apresenta como possibilidade e tentar transcender dentro das condições de escolhas (CASTRO; EHRLICH, 2016).

\footnotetext{
Disse e repetirei as razões objetivas pelas quais estou com vocês. Uma das razões subjetivas é que os maoístas me rejuvenescem por suas exigências... Só que, a partir dos setenta anos, se persistimos em misturar-nos com pessoas que agem, somos transportados aos lugares de carro com uma cadeira de abrir e fechar, somos um incomodo para todo mundo e a idade nos transforma em ornamento. Digo isto sem melancolia: preenchi bem minha vida, estou satisfeito ... "E estou satisfeito com suas vinculações comigo. É óbvio que só existo para vocês na medida em que lhes sou útil. Aprovo isso inteiramente. Mas quando se trata de realizar ação em comum, existe amizade, isto é, uma relação que ultrapassa a ação empresa, uma relação de reciprocidade ...Eis o sentido profundo de minha relação com vocês (BEAUVOIR, 2012, p. 58).
}

Para Menezes e Lopes (2013), o envelhecer passa pela ação do tempo na vida do homem, causando um sentimento de esgotamento físico, gerando um entendimento mais próximo da possibilidade da morte biológica. No entanto se o ser humano existe para morte, então nada mais autêntico que buscar aceitar e compreender sua morte como algo possível e inevitável, mesmo que no cotidiano da sociedade a morte não seja encarada como algo a ser considerado, por isso possível de se buscar fugir de tal fenômeno, porém 
o mais certo é que um dia ela virá. Sendo assim a pessoa idosa vivencia, pouco a pouco, essa expectativa da morte na experimentação das perdas cotidianas no seu processo de envelhecimento. Apesar do luto e perdas, as pessoas idosas têm mais possibilidade de dar um sentido pleno a sua existência e apesar de parecer que chegar a velhice seja andar lado a lado com a morte, ainda há muito que se fazer, e ser.

Passamos uma noite agradável ontem," disse-lhe. Ele hesitou: "Sim. Mas, ontem à noite, eu estava achando que era invisível." "Você não mencionou isso." "Foi depois que cheguei. Sentia-me em perigo com relação às pessoas. Então, pensei que era invisível." Como eu insistisse, disse-me que não tinha medo de ninguém em particular, mas que tinha a impressão de ser um objeto, sem relação com as pessoas. "Mas você tem relações com elas (BEAUVOIR, 2012, p. 68).

A não relação com as coisas coloca seu projeto em questionamento, como se estivesse vazio ou sem relação com as pessoas, ou como o próprio escritor fala "pensei que era invisível," ou seja, como algo que não existe mais, pois não está em relação com o mundo um mero objeto. Isso remete ao estudo de Schneider (2011) que fala sobre a relação com o corpo e a experiência psicofísica, onde o mundo age como uma força sobre as ações do sujeito, e observar essas experimentações concretas, ao investigar a relação do sujeito com o mundo e as coisas assim pode compreender a dinâmica psicológica que o sujeito vive. Sendo assim a relação com as coisas e o outro no mundo dão forma ao projeto de ser, portanto quando Sartre fala que teve medo de não estar em relação com as pessoas e de ser somente um objeto, isso impossibilita a continuidade do seu projeto, tornando-o assim um ser para a morte, pois já não vê a possibilidade de se viabilizar com a liberdade de escolhas. "numa vida acabada, é o fim que se toma pela verdade do começo. $\mathrm{O}$ defunto permanece a meio caminho entre o ser e o valor, entre o fato bruto e a reconstrução; sua história torna-se uma espécie de essência circular que se resume em cada um de seus momentos" (SARTRE, 1967, p. 127).

Havia nele uma apatia em relação as coisas, nada o alegrava muito e constantemente parecia estar ausente, como que se estivesse vazio, longe, uma tristeza se abatia, frequentemente se achava desligado e sonolento, as vezes se mostrava um rosto como que entorpecido, cansava-se facilmente de qualquer coisa, constantemente a impressão era de estar velho sem energia, sem forças para continuar seu caminho de escolha, isso parecia frequentemente trazer sobre ele um melancolia, uma tristeza passiva em relação as situações que se apresentavam. "Ele não deu nenhuma esperança: a hemorragia cicatrizava, mas o meio da retina conservava marcas indeléveis, estava necrosado. Sartre me disse ao sair; "Então já não poderei ler?" Encolheu-se no táxi que nos conduzia de volta e pôs-se a cochilar" (BEAUVOIR, 2012, p. 90).

Essa prostração se dá pelo fato que a construção do seu projeto está ligada à escrita, e o impedimeto da leitura pela visão comprometida, o entristece, já não podia realizar seu projeto de ser como desejava, há um corte em seu projeto que o inviabilizava de estar em meio aos livros, causando um impasse no seu transcender rumo ao futuro, pois o próprio escritor falava, "Escrevendo, eu existia, escapava aos adultos: mas eu só existia para escrever, e se eu dizia eu, isso significava: eu que escrevo" (SARTRE, 1967, p. 96).

Para Sartre (2008), a tristeza passiva tem essa característica de abatimento como se encontra na narrativa das experimentações do próprio escritor, essa tristeza se apresenta como uma diminuição do tônus muscular, palidez apatia, a pessoa quer ficar quieta, sozinha, como que isolada do mundo prefere a penumbra da luz, foge das multidões. Esse tipo de tristeza busca suprimir a obrigações de criar novos meios de realizar as escolhas no mundo em que está inserido, passando a substituir por uma indiferença, fazendo do mundo uma realidade afetiva neutra. Desse modo, por querer e não poder realizar as ações que levam a construção contínua do projeto de ser, o indivíduo passa a tentar ver como se o universo nada mais exigisse dele, tentando manter-se neutro, apático, perante a realidade que se apresenta, tomando uma posição de recolhida, se encolhendo em uma atitude de refúgio da realidade, buscando uma proteção dos desaparecimentos das condições ordinária da ação no mundo, passando a não ter condições de encarar a mudança que se apresenta no caminho. 
Os acontecimentos ligados ao seu processo de envelhecimento o deixavam cada vez mais triste com uma prostração, por não poder realizar-se, embora desejasse seguir com seu projeto de ser, as doenças e as intemperanças da vida, geravam obstáculos para a viabilização de seu projeto, pois já não podia escrever e nem ler, caminhava com dificuldade, estava impedido de acompanhar as manifestações, tinha dores na boca e não podia palestrar como antes, tudo isso levava a uma tristeza passiva, um abatimento, uma espécie de vazio, "estava tão silencioso que lhe perguntei: em que está pensando?" "Em nada. Não estou presente". "Onde está?" "Em nenhum lugar. Estou vazio." Esse tipo de ausência era frequente. (BEAUVOIR, 2012, p. 93)

Conforme Beauvoir (2012), Sartre passa a ter experimentações inquietas e difusas sobre seu corpo, sua idade e sua morte. Sua saúde piorava, também bebia muito e fumava. Começava a ressentir-se por não trabalhar, achava que estava ficando velho e gagá, mas gostava de viver. As vezes parecia com o rosto intumescido, sua visão estava comprometida, já não conseguia mais caminhar nem ler. Estava com diabetes e ingeria muitas comidas ricas em açúcar. Tinha problemas com seus dentes, sentia fortes dores na boca. Porém o que mais lhe causava aflição era o fato de estar ficando cego, pois já não poderia mais ler, escrever. Estava se tornando cada vez mais impossibilitado de realizar seu projeto. Ele já se sentia ameaçado, "um dia tem que acabar. Afinal, foi feito o que se pode. Foi feito o que havia a fazer" (BEAUVOIR, 2012, p.71).

Um dia, eu afastara a lâmpada de sua poltrona: ele me pediu que a trouxesse de volta. "Você diz que a luz o incomoda"... "Mas preciso dela quando leio." Corrigiu-se: "Bem, quando folheio um livro." Na verdade, não podia já folhear um livro ou lê-lo. Embora quisesse sempre reter por um momento, em suas mãos, os novos volumes que eu lhe trazia.[...] Contudo, uma vez mais, ele me partiu o coração. Olhou para seu escritório: "É estranho pensar que este apartamento é meu." "Ele é muito bom, sabe." "Não gosto mais dele." "Como? Agradava-lhe tanto." "A gente se cansa das coisas." "Você se cansa rápido: eu estou no meu há dezoito anos e sempre me sinto bem lá." "Sim, mas aquele é o lugar onde já não trabalho (BEAUVOIR, 2012, p.91).

Nesse parágrafo encontra-se os primeiros traços do impedimento do projeto de ser que movia o escritor existencialista. Em um primeiro momento se percebe a dificuldade de poder ler os livros devido sua cegueira, mas mesmo assim ele continuava no meio dos livros. Como anteriormente referenciado no livro As palavras, ele queria acabar sua vida do jeito que começou; no meio dos livros. Já não podia mais ler, mas continuava querendo pelo menos senti-los em suas mãos ao folheá-los. Em outro momento aparece a relação já não existente do trabalho citado, como um desgosto de estar no seu escritório, o lugar onde já não pode mais viabilizar-se na construção de seu projeto, se apresentando como uma ausência no sentido de continuidade desse projeto. Tal vivência lhe causa uma interrupção no sentido que se direciona o caminho de totalização em curso."o sentido de um fenômeno qualquer desta vida fica determinado daqui por diante, não por ele mesmo, mas por esta totalidade em aberto que é a vida interrompida. Tal sentido, a título primário e fundamental, é ausência de sentido" (SARTRE, 2015, p. 663)

Eu, mentia a mim mesmo; a fim de despir a morte de sua barbárie, eu a convertera em meu alvo e fazia de minha vida o único meio conhecido de morrer: eu seguia lentamente para meu fim, não alimentando outras esperanças e desejos exceto os necessários para preencher meus livros, seguro de que o último pulso de meu coração se inscreveria na última página do último tomo de minhas obras e que a morte colheria apenas um morto (SARTRE, 1967, p. 126).

O caminho para o seu fim de projeto, se tornou uma possibilidade mais próxima, e a morte passa a ser vista como inevitável. Conforme Beauvoir (2012), o escritor fala que era difícil dizer como estava sua realidade vivida, não podia dizer se estava bem ou mal, mas tinha sua profissão destruída, já não podia mais ler nem escrever, em certo sentido isso tirava toda a razão de ser, se tornava aquilo que ele já foi e não pode ser mais. 
Mas não pensava com tristeza no que tinha perdido, diante disso não podia fazer nada, então não tinha razão para reclamar ou lamentar-se. Falava também da possibilidade real da sua morte, dizia que não pensava constantemente no fim de seu existir, mas tinha certeza que ele viria, não havia como fugir ou evitar o fim do seu projeto de ser, porém falava que estava satisfeito com o que tinha vivido e aceitava o presente com serenidade.

Não queria aborrecer os outros com seus problemas. E a revolta contra um destino inevitável lhe parecia inútil. "É assim e nada posso fazer, então não tenho motivo para desolarme.” Ainda amava a vida ardentemente, mas a ideia da morte, ainda que afastasse seu desfecho até os oitenta anos, lhe era familiar. Aceitou sua chegada sem problemas, sensível às amizades, às afeições que o rodeavam, e satisfeito com seu passado: "Fez-se o que se podia fazer (BEAUVOIR, 2012, p. 166).

Com seu projeto de escritor comprometido, já não podia mais trabalhar, envelhecido, impossibilitado de movimentar-se nem ir e vir na liberdade de seu querer, cada vez mais impedido de se realizar em seu projeto de ser, falava continuamente, foi feito o que tinha que se fazer, como que sua obra estivesse acabada, estava impossibilitado de engajar-se em novos projetos. Sartre já não viveria por muito mais tempo, embora não pudesse saber quanto tempo teria, sabia que o tempo era finito e já não via muitas possibilidades de futuro, a morte já estava presente. "Agora, não esperava muito do futuro. Evidentemente, não se voltava ansiosamente para seu passado. Repetiu muitas vezes: tinha feito o que tinha a fazer e estava satisfeito com isso" (BEAUVOIR, 2012, p. 132).

Internado com o quadro de saúde bastante comprometido, Sartre estava desenganado pelos médicos, que já não podiam fazer mais muita coisa por sua vida, senão deixá-lo morrer em paz, "comecei a soluçar e me atirei nos braços de Housset: "Prometa que ele não se verá morrer, que não sentirá angústia, que não sofrerá!" "Eu lhe prometo, senhora" (BEAUVOIR, 2012, p. 165). Tinha os rins comprometidos por não serem mais irrigados por isso não funcionavam. Para reverter o quadro era preciso uma cirurgia, mas ele não suportaria devido à baixa irrigação de sangue no cérebro, já havia sofrido vários acidentes vasculares encefálico, sua circulação sanguínea era falha e por isso causava gangrena no corpo criando escaras terríveis. Dormia muito, mas conservava a lucidez, chegando a questionar sobre os gastos com o enterro. Em muitas vezes não era a morte que o preocupava, mas sua cegueira e seu cérebro, porém suportava com humildade tudo que lhe acontecia, pois, a revolta contra um destino inevitável parecia inútil. Fez-se o que podia fazer. Após toda essa longa trajetória que durou essa cerimônia do adeus, as 9:00 horas do dia 15 de abril de 1980 chega ao fim a vida de Jean-Paul Sartre. “Às nove horas, o telefone tocou. Ela me disse: «Terminou.» Fui para lá com Sylvie. Ele estava igual a ele mesmo, mas já não respirava” (BEAUVOIR, 2012, p. 167).

Ele não tinha nenhuma disposição a tomar, não poderia ter-se tratado melhor do que foi. E amava a vida. Já tinha tido muita dificuldade em assumir sua cegueira, suas enfermidades. Se tivesse sabido com mais exatidão a ameaça que pesava sobre ele, isso apenas entristeceria inutilmente seus últimos anos. De toda maneira, eu oscilava como ele entre o temor e a esperança. Meu silêncio não nos separou. Sua morte nos separa. Minha morte não nos reunirá. Assim é: já é belo que nossas vidas tenham podido harmonizar-se por tanto tempo (BEAUVOIR, 2012, p.170).

Quando se fala em despedida, há um envolvimento do outro no processo de morte. Nesse caso, Simone de Beauvoir que vive intensamente de forma particular todo o caminho trilhado até a despedida. Sempre envolvida profundamente nas experimentações da finitude, elaborando seu luto nas mediações, sendo cuidadora. De certa forma experimentando a angústia da finitude humana na trajetória da cerimônia do adeus. "Este estúdio, tão alegre desde meu regresso, mudou de cor. O bonito tapete escuro evoca um luto. É assim que será preciso viver, talvez ainda como felicidades e momentos de alegria, mas com o peso da ameaça, a vida colocada entre parênteses” (BEAUVOIR, 2012, p. 21). 
Para Santos e Sales (2011), o processo de luto é vivido por cada pessoa de forma individual e a morte de uma pessoa próxima torna o outro um ser enlutado, no qual a ausência gera um luto que tem de ser enfrentado e elaborado. Nesse sentido, o cuidador envolve-se na possibilidade de conhecer-se num mundo de experimentações que estão diretamente ligadas a compreensão de seu existir no mundo, de certa forma passa por um aprendizado estando ao lado do ser para morte, fazendo pensar na possibilidade do fim, pois compartilha seu existir na proximidade da morte. Com isso a pessoa passa a refletir melhor sobre seu próprio fim e de certa forma descobre que sua existência é finita, e acaba buscando um equilíbrio e entendimento, fato que faz repensar sua existência. O que se pode afirmar com certeza é que a morte será sentida pela pessoa que fica e que esta necessita de meios para expressar o seu pesar.

\section{CONSIDERAÇÕES FINAIS}

A contribuição da psicologia fenomenológica existencialista para o estudo da morte como fim do projeto de ser, tem a importância de trazer consigo um olhar mais objetivo sobre a realidade da existência humana, como ela se faz em meio as escolhas no mundo e que essas ações dão delineamento ao projeto de ser, bem como o seu caminho de ser para a morte, visto que a morte é algo inerente ao ser humano, que ninguém pode escapar de tal realidade, que mesmo sendo a morte o último momento da vida ainda assim é vida. Com isso o estudo da trajetória do projeto de ser de Jean-Paul Sartre, pode ajudar a compreender o início do projeto de ser, bem como o término que acontece com a impossibilidade do futuro gerado pela morte, pois acaba com qualquer possibilidade de transcendência do ser no mundo.

Ao levantar uma discussão sobre os aspectos da morte e a finitude dos seres humanos, e que o projeto de ser, não há um fim demarcado, mas é acometido pelo absurdo do impedimento de realizar-se, pelo fenômeno inevitável da morte, busca-se com esse estudo, possibilitar, uma reflexão sobre a morte como fim do projeto de ser, para tentar entender melhor o fenômeno da finitude humana, ao abordar o assunto pautado em uma psicologia científica.

Na prática da psicologia são comuns os questionamentos sobre a morte, pois esse fenômeno pode gerar complicações psicológicas. Seja ela ligada ao sofrimento psicológico do indivíduo que antecipa seus medos do desconhecido, gerado um temor da morte. Podendo aparecer também o desespero por não conseguir lidar com a realidade em que vive e por não achar meios de viabilizar-se no mundo. Ou ainda complicações ligadas ao processo de elaboração de lutos por aqueles que não encerraram seus projetos. Tais complicações fazem parte da realidade do existir humano e devem ser amplamente discutidas com finalidade de conscientizar e diminuir o sofrimento de perdas, lutos bem como amenizar o desespero humano perante a morte (FISCHER, 2007).

A importância de entender a terminalidade humana é um assunto que precisa ser mais abordado na prática da construção do pensamento científico. Visto que há pouca criação de produções científicas voltados ao estudo da tanatologia, porém a todo momento as pessoas passam por situações de perdas e luto, e se faz nescessário falar sobre o assunto, já que todo o ser humano faz parte de uma sociedade e está imerso em uma determinada cultura, vivendo na sua liberdade de escolhas. Sendo assim o assunto da morte deve ter mais espaço dentro das discussões nos meios acadêmicos, por ser um fenômeno inerente ao existir, pois se por um lado a morte na atualidade é um assunto velado ou um tabu do qual não se faz nescessário nem pensar, por outro lado o ser humano encontra-se cercado por situações de perdas, algo que possibilita o aumento do desespero humano em torno da morte. Sendo assim, discutir o processo de construção do projeto de ser e a finitude do mesmo, pautado em uma psicologia científica que possa ajudar a entender a morte como fenômeno natural da vida, tem o objetivo de contribuir significativamente na compreensão da finitude humana, fazendo com que a antecipação do sofrimento possa ser diminuida e até mesmo a elaboração do luto possa acontecer em menor tempo. Por fim, mesmo sendo um absurdo, a morte é a última etapa do processo na completude do existir humano. 


\section{REFERÊNCIAS}

BEAUVOIR, Simone. A cerimônia do adeus - edição especial-. Rio de Janeiro: nova fronteira, 2012. Tradução Rita Braga.

CASTRO, Fernando Gastal de; ZANELLI, José Carlos. Síndrome de burnout e projeto de ser. Cadernos de Psicologia Social do Trabalho, São Paulo, v. 10, p.17-33, 2007. Disponível em: <http://http://www.revistas.usp.br/cpst/article/ viewFile/25798/27531>. Acesso em: 01 set. 2017.

CASTRO, Fernando Gastal de; EHRLICH, Irene Fabricia. Introdução à psicanálise existencial: existencialismo, fenomenologia e projeto de ser. Curitiba Pr: Jurua, 2016. 250 p.

EHRLICH, Irene Fabrícia. Contribuições do "Projeto de Ser" em Sartre para a Psicologia de Orientação Profissional. 232 f. Dissertação (Mestrado) - Curso de Psicologia., Centro de Filosofia e Ciências Humanas Programa de Pós-graduação em Psicologia, Universidade Federal de Santa Catarina, Florianópolis, 2002. Disponível em: $<$ https:// repositorio.ufsc.br/bitstream/handle/123456789/83679/223397.pdf?sequence=1>. Acesso em: 01 set. 2017.

FISCHER, Joyce Mara Kolinski. Manual de tanatologia -21 a ed- Curitiba: Gráfica e Editora Unificado, 2007.

GIL, Antonio Carlos. Como elaborar projetos de pesquisa. -4ed- São Paulo: atlas, 2002.

HEIDEGGER, Martin. Ser e tempo. 13. ed. Petrópolis: Vozes, 2005. Tradução Marcia Sá Cavalcante Schuback.

KOVÁCS, Maria Julia. A caminho da morte com dignidade no século XXI. Revista Bioética, Brasília, v. 22, p.94-104, 2014. Disponível em: <http://www.scielo.br/scielo.php?script=sci_arttext\&pid=S198380422014000100011\&lng=pt\&tlng=pt $>$. Acesso em: 01 set. 2017.

KUBLER-ROSS, Elisabeth. Sobre a morte e o morrer: o que os doentes terminais tem para ensinar a médicos, enfermeiras, religiosos e aos seus próprios parentes. São Paulo: Wmf Martins Fontes, 2008.

MENEZES, Tânia Maria de Oliva; LOPES, Regina Lúcia Mendonça. Significados do vivido pela pessoa idosa longeva no processo de morte/morrer e luto. Ciência \& Saúde Coletiva, Salvador Ba, p.3309-3316, 29 jul. 2013. Disponível em: <http://www.scielo.br/pdf/csc/v19n8/1413-8123-csc-19-08-03309.pdf>. Acesso em: 03 out. 2017.

PAPALIA, Diane E.; FELDMAN, Ruth Duskin. Desenvolvimento humano. 12. ed. Porto Alegre: Amgh, 2013.800 p.

ROTHSCHILD, Daniela e CALAZANS, Rauflin Azevedo. Morte-Abordagem Fenomenológica-existencial. In Morte e Desenvolvimento Humano. $5^{\text {a }}$ ed., São Paulo/Casa do Psicólogo, 2008.

SANTOS, Elionésia Marta dos; SALES, Catarina Aparecida. Familiares enlutados: compreensão fenomenológica existencial de suas vivências. Texto \& Contexto - Enfermagem, Florianópolis SC, v. 20, p.214-222, 2011. Disponível em: $<$ http://www.scielo.br/pdf/tce/v20nspe/v20nspea27.pdf>. Acesso em: 03 out. 2017.

SARTRE, Jean-Paul. As Palavras. 3. ed. São Paulo: Difusão Europeia do Livro, 1967.

SARTRE, Jean-Paul. Esboço para uma teoria das emoções. Porto Alegre Rs: L\&pm editores, 2008. Tradução Paulo Neves.

SARTRE, Jean-Paul. O existencialismo é um humanismo. 3. ed. Petrópolis Rj: Vozes, 2014.

SARTRE, Jean-Paul. O ser e o nada. 24. ed. Petrópolis: Vozes, 2015. Tradução Paulo Perdigão.

SILVA, José Cordero da. O fim da vida: uma questão de autonomia. Nascer e Crescer, Porto, v. 23, p.100-105, 2014. Disponível em: <http://www.scielo.br/pdf/csc/v19n8/1413-8123-csc-19-08-03309.pdf>. Acesso em: 01 set. 2017.

SCHNEIDER, Daniela Ribeiro. Sartre e a psicologia clínica. Florianópolis: Ufsc, 2011. 


$\begin{array}{ll}\text { Histórico } & \begin{array}{l}\text { Recebido em: } 25 / 05 / 2019 \\ \text { Revisado em: 08/10/2019 } \\ \text { Aceito em: 05/12/2019 }\end{array} \\ & \begin{array}{l}\text { Concepção: IF; WAL } \\ \text { Coleta de dados: WAL }\end{array} \\ & \text { Análise de dados: IF; WAL } \\ \text { Elaboração do manuscrito: WAL } \\ \text { Revisões críticas de conteúdo intelectual importante: IF } \\ \text { Aprovação final do manuscrito: IF; WAL } \\ \\ \text { Financiamento }\end{array}$

